\title{
Cyclin-dependent kinase inhibitors in brain cancer: current state and future directions
}

\author{
Viktorija Juric, Brona Murphy \\ Department of Physiology and Medical Physics, Royal College of Surgeons in Ireland, Dublin D02, Ireland.
}

Correspondence to: Dr. Brona Murphy, Department of Physiology and Medical Physics, Royal College of Surgeons in Ireland, 39A York Street, Dublin D02, Ireland. E-mail: bronamurphy@rcsi.com

How to cite this article: Juric V, Murphy B. Cyclin-dependent kinase inhibitors in brain cancer: current state and future directions. Cancer Drug Resist2020;3:48-62. http://dx.doi.org/10.20517/cdr.2019.105

Received: 5 Nov 2019 First Decision: 4 Dec 2019 Revised: 11 Dec 2019 Accepted: 20 Dec 2019 Published: 19 Mar 2020

Science Editor: Lee M. Graves Copy Editor: Jing-Wen Zhang Production Editor: Jing Yu

\begin{abstract}
Cyclin-dependent kinases (CDKs) are important regulatory enzymes in the normal physiological processes that drive cell-cycle transitions and regulate transcription. Virtually all cancers harbour genomic alterations that lead to the constitutive activation of CDKs, resulting in the proliferation of cancer cells. CDK inhibitors (CKIs) are currently in clinical use for the treatment of breast cancer, combined with endocrine therapy. In this review, we describe the potential of CKIs for the treatment of cancer with specific focus on glioblastoma (GBM), the most common and aggressive primary brain tumour in adults. Despite intense effort to combat GBM with surgery, radiation and temozolomide chemotherapy, the median survival for patients is 15 months and the majority of patients experience disease recurrence within 6-8 months of treatment onset. Novel therapeutic approaches are urgently needed for both newly diagnosed and recurrent GBM patients. In this review, we summarise the current preclinical and clinical findings emphasising that CKIs could represent an exciting novel approach for GBM treatment.
\end{abstract}

Keywords: Cyclin-dependent kinases, cyclin-dependent kinase inhibitors, gliomas, glioblastoma, clinical trials, resistance

\section{INTRODUCTION}

Cyclin-dependent kinases (CDKs) are a family of enzymes-serine threonine kinases - that, under normal physiological conditions, play significant roles in controlling cell-cycle progression and transcription regulation $^{[1]}$. Overexpression of some CDKs and their associated cyclins, as well as downregulation of

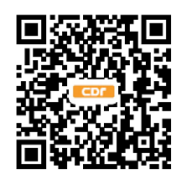


CDK inhibitors (CKIs), can lead to abnormal cellular proliferation and cancer progression ${ }^{[2]}$. Due to such dysregulation of CDKs in many cancers, targeting of this family of enzymes has emerged as a promising strategy in the treatment of multiple cancer types, including blood and solid tumours ${ }^{[3,4]}$. Targeting the cell cycle via the CDK4/6-Rb axis has proven the most successful approach in the clinic to date. The FDA has approved the CDK4/6 inhibitors palbociclib, abemaciclib and ribociclib as treatments for hormone receptor-positive (HR+) metastatic breast cancer $(\mathrm{mBC})$, in combination with endocrine therapy ${ }^{[5-7]}$.

Glioblastoma (GBM) tumours also harbour genomic alterations that lead to the constitutive activation of CDKs, resulting in tumour proliferation ${ }^{[8]}$. Hence, the potential of CKIs as a novel treatment option for GBM patients has been investigated. Preclinical studies in cell lines and animal models have yielded positive results and provided hope for the future utilisation of these inhibitors as a novel treatment option for GBM patients ${ }^{[9,10]}$. However, clinical trials undertaken to test CKIs in glioma patients have not proven successful ${ }^{[11]}$. In this review, we discuss the main findings from the application of CKIs as a potential treatment for glioma, in both preclinical and clinical studies. We highlight the main drawbacks and examine the future opportunities in developing these drugs as single or combinational treatment options for glioma patients with the specific focus on GBM.

\section{GBM: STANDARD OF CARE AND TREATMENT RESISTANCE}

Gliomas represent the most common primary malignancy in the central nervous system (CNS) including astrocytomas, oligodendrogliomas and ependymomas and account for approximately 80\% of malignant brain and CNS tumours ${ }^{[12]}$. Based on clinical and biological characteristics, gliomas can be subdivided into two main categories, low-grade glioma and high-grade glioma. Based on their histological appearance, the World Health Organisation (WHO) categorises gliomas using a classification index, ranging from I to IV, which grades gliomas according to disease prognosis ${ }^{[13]}$. WHO grades I and II have been referred to as lowgrade gliomas, with a possibility of cure following surgical resection alone, while more rapidly progressing tumours are referred to as high-grade gliomas. Grade III neoplasms are associated with histological signs of malignancy, nuclear atypia, mitotic activity and high proliferative lesions. GBM is the highestgrade glioma tumour (Grade IV) and the most malignant form of astrocytic glioma with extremely poor treatment response and prognosis ${ }^{[1,1,1]}$. Two types of GBM usually occur: primary and secondary. Primary GBM develops de novo from glial cells or supportive tissues of the brain, accounts for approximately $90 \%$ of GBM cases and is more common in older patients. Secondary GBMs develop from pre-existing lowgrade gliomas, accounting for $10 \%$ of GBM cases and are more common in younger patients ${ }^{[15]}$. Some DNA alterations are shared between primary and secondary GBM, including TP53 mutations and EGFR overexpression $^{[16]}$. On the other hand, loss of PTEN has been typically observed only in primary GBM, whereas secondary GBM often contains loss of chromosome 19q along with TP5 $3^{[17,18]}$. As for the median survival rate, primary GBM shows worse prognosis when compared to secondary GBM following maximal therapy, with overall survival of 15 months and 31 months, respectively ${ }^{[19]}$. Using genomic profiling to classify GBM tumours, Verhaak et al. ${ }^{[20]}$ divided GBM into four subtypes. Proneural, mesenchymal, classical and neural subtypes were distinguished upon analysis of an 840 -gene signature ${ }^{[20]}$. Proneural subtype is described as being less aggressive with some similarities to secondary GBM, including mutations of TP53 contributing to the genetic changes that lead to tumour progression ${ }^{[21-23]}$. Additionally, alterations of PDGFRA and point mutations in $I D H 1$ are found in the proneural subtype ${ }^{[20]}$. On the other hand, mesenchymal, classical and neural subtypes are more aggressive with high expression of genes responsible for cell proliferation, angiogenesis and invasion ${ }^{[24]}$. Classical subtype is characterised by high levels of EGFR amplification which is not commonly found in other subtypes. CDKN2A homozygous deletion is also commonly found in this subtype ${ }^{[20]}$. Interestingly, a lack of TP53 mutations is observed in the classical subtype even though it is the most common mutation in $\mathrm{GBM}^{[25]}$. Mesenchymal subtype is characterised by a high frequency of NF1 abnormalities and markers associated with inflammation, wound healing, and 
$\mathrm{NF}-\mathrm{\kappa B}$ signalling pathways ${ }^{[20,24]}$. Neural subtype is associated with EGFR overexpression and has a strong enrichment for genes differentially expressed by neurons ${ }^{[20]}$. More recently, the neural subtype has been discarded as it showed no tumour specificity in a gene set enrichment analysis using a 50-gene signature per subtype ${ }^{[26]}$. Other types of classification are known and, while such subtyping of GBM tumours will hopefully lead to more targeted therapies in the future, such classifications are not currently applied in the clinic.

The standard treatment for newly diagnosed GBM patients consists of maximal neurosurgical resection with the overall aim to remove all visible tumour such that no tumour is observed post-surgery upon magnetic resonance imaging. Following surgery, adjuvant treatment is advocated and the so-called Stupp protocol is widely used ${ }^{[27]}$. According to this protocol, patients should receive concomitant radiotherapy (RT) and temozolomide (TMZ) followed by adjuvant TMZ. Radiotherapy consists of fractionated focal irradiation at a dose of 2 Gray (Gy) per fraction given once daily, five days per week over a period of six weeks, for a total dose of 60 Gy. Concomitant chemotherapy consists of TMZ at a dose of $75 \mathrm{mg} / \mathrm{m}^{2}$ per day, given seven days per week during radiotherapy. Upon completion of chemo- and radiotherapy, there should be a 4-week break. After that, patients should receive up to 6 cycles of adjuvant TMZ, given for five days every 28 days, with a starting dose of $150 \mathrm{mg} / \mathrm{m}^{2}$ for the first cycle. This dose is subsequently increased to $200 \mathrm{mg} / \mathrm{m}^{2}$ at the beginning of the second cycle, as long as there are no hematologic toxic effects ${ }^{[28]}$. To date, the addition of TMZ to the armamentarium remains the biggest significant advance in the management of GBM. When successful, TMZ induces cell death by causing DNA double strand breaks that eventually lead to growth arrest and activation of cellular apoptosis ${ }^{[29,30]}$. Unfortunately, however, its benefit is limited to prolonging patient survival rather than being a curative treatment adjunct. Most patients experience tumour relapse within seven months of treatment onset, while a large proportion gain no survival advantage to TMZ therapy at all ${ }^{[31]}$. Several factors contribute to this poor survival, including but not limited to, patient condition, tumour location, and the heterogeneous instability within GBM cells ${ }^{[32]}$. Another potential mechanism of treatment failure is the blood-brain barrier (BBB), which consists of specialised endothelial cells with tight junctions and transport proteins that serves to restrict brain uptake of drugs, including systemic chemotherapies ${ }^{[33]}$. Another significant factor in such disappointing patient survival rates is TMZ resistance. TMZ, as well as most other anti-cancer therapies, exerts its cytotoxic effect by triggering apoptosis in cancer cells ${ }^{[30,34]}$, thus defective apoptosis provides a significant mechanism by which TMZ treatment fails in patients. A key marker of GBM responsiveness to TMZ is the methylation status of the O6-methylguanine-DNA methyltransferase (MGMT) ${ }^{[27]}$. MGMT mediates the direct removal of O6-methylguanine lesion, the most common cytotoxic lesion induced by TMZ. Approximately 50\% of GBM patients do not respond to TMZ treatment, most likely due to MGMT overexpression, while epigenetic silencing of MGMT via methylation of the MGMT gene promoter results in increased genome instability and chemosensitivity to $\mathrm{TMZ}^{[35]}$. Overexpression of numerous survival proteins and attenuated levels of several proapoptotic proteins also contribute to the apoptosis resistance in $\mathrm{GBM}^{[36]} ; \mathrm{Bcl}-2, \mathrm{Bcl}-\mathrm{xL}$, Bax and myeloid cell leukemia $1(\mathrm{Mcl}-1)$ proteins are among most studied so far ${ }^{[37]}$.

Undoubtedly, new treatment options are needed. Maximising the apoptotic activity within GBM cells, by using other death-inducing stimuli, may help to reduce the resistance of GBM to cell death-inducing treatment strategies ${ }^{[38]}$. Recent studies showed that the treatment resistance evident in GBM can be overcome by using drugs targeting not only the expression of anti-apoptotic proteins but also those that target cell-cycle dysregulation ${ }^{[39]}$, including but not limited to, CDK4/6/cyclin D overexpression. These attributes are evident in CKIs.

\section{CDKS AND THEIR PHYSIOLOGICAL ROLE}

The mammalian CDK family has more than 20 known members ${ }^{[3]}$. The first CDK, now known as CDK1, was discovered in yeast where it was shown to be essential for progressing the cell cycle ${ }^{[40]}$. Soon after 
Table 1. Most extensively studied CDKs and their known physiological roles

\begin{tabular}{lllc}
\hline CDKs & Cyclin partner(s) & Cellular functions & Ref. \\
\hline CDK1 & Cyclin A, B1 & DNA structure checkpoints during late G2 and the spindle assembly checkpoint during mitosis & {$[44,45]$} \\
CDK2 & Cyclin A & Control of G1-S phase of cell cycle (DNA replication) & {$[44,45]$} \\
& Cyclin E1, E2 & Rb/E2F transcription & {$[44,45]$} \\
CDK3 & Cyclin C & Control of interphase NHEJ-mediated DNA damage repair & {$[46]$} \\
CDK4 & Cyclin D & Control of G1 phase of cell cycle Rb/E2F transcription & {$[47]$} \\
CDK5 & p35, p39, Cyclin I & Senescence, post-mitotic neurons & {$[52-54]$} \\
CDK6 & Cyclin D & Control of G1 phase of cell cycle Rb/E2F transcription & {$[50]$} \\
CDK7 & Cyclin H & CAK RNAP II transcription (initiation to elongation) \\
CDK8 & Cyclin C & RNAP II transcription (transcriptional repressor) & {$[55-57]$} \\
CDK9 & Cyclin T1, T2a, T2b RNAP II transcription & {$[58,59]$} \\
& Cyclin K & DNA damage response & {$[60,61]$} \\
CDK10 & Cyclin T & G2/M transition, suppression of Ets2 transactivation domain & {$[62]$} \\
CDK11 & Cyclin L & G2/M transition, RNA processing & {$[61,63]$} \\
\hline
\end{tabular}

G1: growth phase; S: DNA synthesis; G2: second growth phase; M: mitosis; CDKs: cyclin-dependent kinases; Rb: retinoblastoma protein; NHEJ: non-homologous end joining; RNAP II: RNA polymerase II; CAK: cdk-activating kinase; E2F: E2 transcription factor; Ets2: E26 transformation-specific transcription factor 2

homologues of CDK1 were identified in human cells ${ }^{[41]}$. Unsurprisingly, the cell-cycle process is strictly controlled to ensure successful cell division. Cyclin-dependent kinases tightly regulate progression through the G1 (growth phase), S (DNA synthesis), G2 (second growth phase) and M (mitosis) phases of the cell cycle, working in conjunction with their associated cyclins ${ }^{[42,43]}$. CDKs 1-4, 6 and 11 control varying aspects of cell division including DNA replication, mitotic progression, and response to regulatory growth signals ${ }^{[44-50]}$. In association with their cyclins, CDKs 2, 4 and 6 regulate progression from G1 to $\mathrm{S}$ phase. $\mathrm{CDK} 3$ is involved in Go and interphase and not much is known about it since it is inactive in most strains of laboratory mice ${ }^{[51]}$. In conjunction with cyclins $\mathrm{E}$ and $\mathrm{A}, \mathrm{CDK} 2$ is involved in regulating progression from $S$ to $\mathrm{G} 2$ phase. CDK1 with cyclins $A$ and $B$ is involved in regulating the G2 phase. Finally, mitosis is under the control of CDK1-CycB and CDK11-CycL complexes [Table 1 and Figure 1].

The kinase activity of CDK-cyclin complexes is also highly controlled by an abundance of CKIs, which serve as brakes to control cell-cycle progression according to the conditions in cells ${ }^{[64]}$. CKIs are divided into two groups. The Ink4 family members, including $\mathrm{p} 16^{\mathrm{INK} 4 \mathrm{a}}, \mathrm{p} 15^{\mathrm{INK} 4 \mathrm{~b}}, \mathrm{p} 18^{\mathrm{INK} 4 \mathrm{c}}$ and $\mathrm{p} 19^{\mathrm{INK} 4 \mathrm{~d}}$, are mainly involved in the regulation of CDKs 4 and $6^{[65]}$. On the other hand, the Cip/Kip family members, namely $\mathrm{p} 21^{\mathrm{Cip} 1}, \mathrm{p} 27^{\mathrm{Kip} 1}$ and $\mathrm{p} 57^{\mathrm{Kip} 2}$, regulate the activities of cyclin D-, E-, A- and B-dependent kinase complexes, mostly CDKs 2, 4 and $6^{[66-68]}$ [Figure 1]. Moreover, an important substrate for CDKs is the retinoblastoma protein $(\mathrm{Rb})^{[69,70]}$. During cell division, $\mathrm{Rb}$ binds to the transcription factor E2 transcription factor (E2F) and inhibits the activity of the E2F complex, thus preventing cell-cycle progression from the G1 phase to the $\mathrm{S}$ phase ${ }^{[71]}$. Phosphorylation of $\mathrm{Rb}$ is primarily initiated by the $\mathrm{CDK} 4 / \mathrm{CDK} 6-\mathrm{CycD}$ complex, followed by additional phosphorylation by the $\mathrm{CDK} 2-\mathrm{CycE} \operatorname{complex}^{[72]}$, resulting in the inactivation of $\mathrm{Rb}$ and cellcycle progression ${ }^{[69,73,74]}$ [Figure 1].

Besides their well-established function in the cell cycle, it is now clear that CDKs, cyclins and CKIs play crucial roles in other cellular processes such as transcription, mRNA processing, epigenetic regulation, metabolism, stem cell self-renewal and differentiation of nerve cells ${ }^{[75]}$. For instance, CDKs 8 and 9 are primarily implicated in transcriptional regulation ${ }^{[75-77]}$ [Table 1 and Figure 2]. Phosphorylation of a key threonine residue located within the activating segment, also known as T-loop, of the CDK subunit is required for full kinase activity ${ }^{[55]}$. This step is carried out by the CDK-activating kinase, known as CDK7, which becomes activated by binding to cyclin $\mathrm{H}$. CDK9, together with cyclin T1, comprises a positive transcription elongation factor $b$, which plays a key role in the regulation of RNA polymerase II (RNAP II)-mediated transcription via phosphorylation of RNAP $\mathrm{II}^{[60]}$. This phosphorylation releases RNAP II from its paused state, triggering transcriptional elongation and ultimately mRNA transcript 


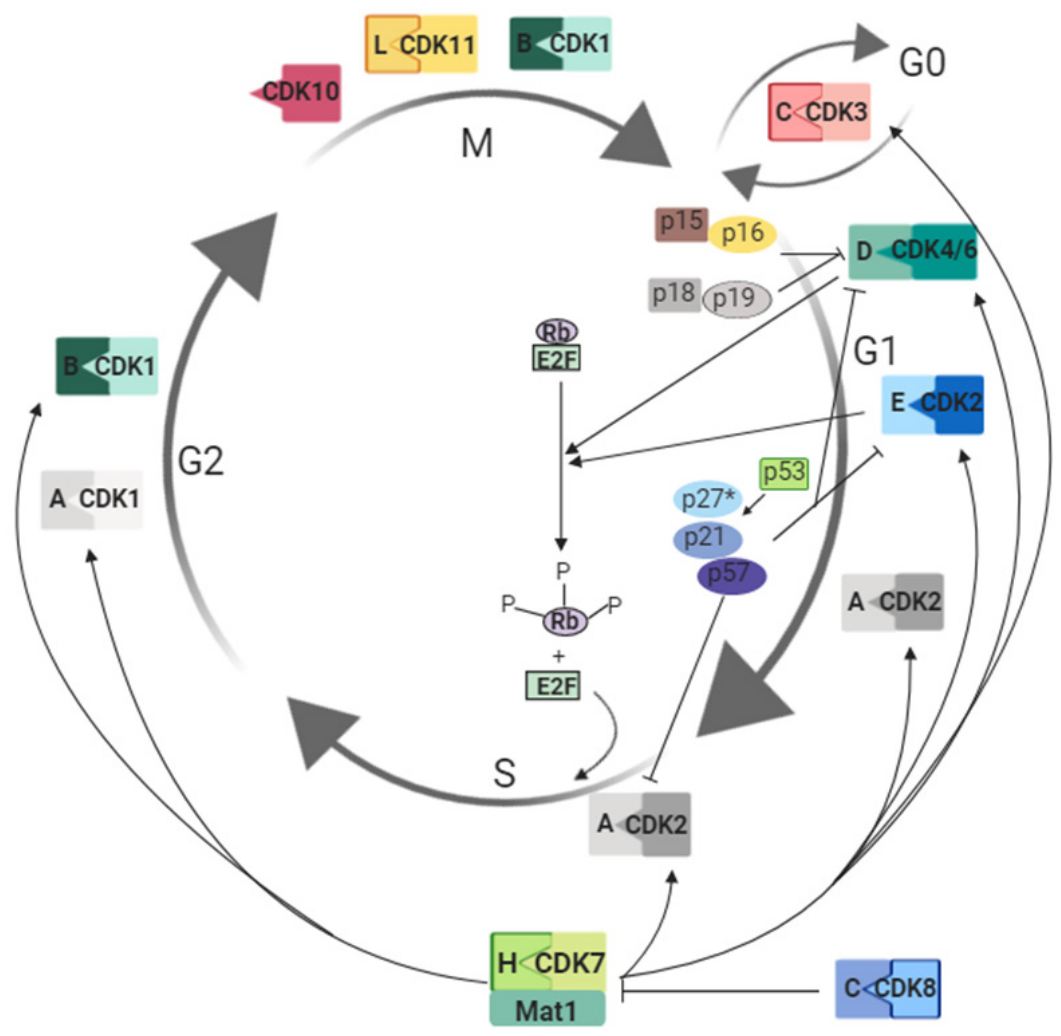

Figure 1. CDK-cyclin complexes and their function in cell cycle. Each CDK is shown in complex with its corresponding cyclin. For clarity, only few substrates are included. CDKs 1, 2, 4 and 6 are classical CDKs involved in the regulation of cell-cycle progression and transition from $\mathrm{G} 1$ to $\mathrm{S}$ phase. CDK1 in complex with cyclins $A$ and $B$ regulate $\mathrm{G} 2 / \mathrm{M}$ transition and mitosis together with CDK11-CycL. CDK3 is involved in the control of the cell-cycle interphase. Activity of these CDK-cyclin complexes is regulated by other CDKs including CDK7 (in complex with its cyclin $\mathrm{H}$ and Mat1), CKIs (p15, p16, p18, p19, p27, p21 and p57) and regulatory elements such as the Rb. CDK7 functions in the regulation of several other CDKs via phosphorylation and is controlled by CDK8 in complex with its cyclin C. *Nonphosphorylated p27. Single letters stand for cyclins, for instance $\mathrm{H}$ is cyclin H. CKIs: cyclin-dependent kinase inhibitors; CDK: cyclin-dependent kinase; $\mathrm{Rb}$ : retinoblastoma protein; G1: growth phase; S: DNA synthesis; G2: second growth phase; M: mitosis; GO: resting phase; E2F: E2 transcription factor

formation. CDK5 is mostly active in post-mitotic neurons and is essential for neuronal cell-cycle arrest and differentiation ${ }^{[52]}$. In addition, some studies have shown dysregulation of CDK5 in neuronal diseases such as Alzheimer's disease, Parkinson's disease and Huntington's disease, leading to neurotoxicity ${ }^{[52]}$. In contrast to other CDKs, CDK5 is activated by binding to p35 and p39, which have structural homologies to typical cyclins ${ }^{[53]}$ but can also be activated by cyclins ${ }^{[54]}$. Inhibition of transcriptional CDKs primarily affects the accumulation of transcripts with short half-lives, including anti-apoptotic family members, Mcl-1 and X-linked inhibitor of apoptosis protein (XIAP) ${ }^{[10,78]}$.

\section{CKIs AS APPROVED TARGETED THERAPY IN CANCER TREATMENT}

The essential roles of CDKs in the intracellular control of the cell cycle and regulation of transcription and DNA repair ${ }^{[79]}$ make them highly suitable as targets of inhibitors for the treatment of cancer.

Separate Phase III clinical trials using CDK4/6 inhibitors, palbociclib, abemaciclib and ribociclib showed an increase in median progression-free survival (PFS) of patients, approximately 7-10 months, when compared to placebo treated groups ${ }^{[5-7]}$. These highly selective CDK4/6 inhibitors are currently used clinically for the treatment of $\mathrm{HR}+\mathrm{mBC}$ patients and were the first CKIs to receive FDA approval for cancer patients ${ }^{[5-7]}$. 

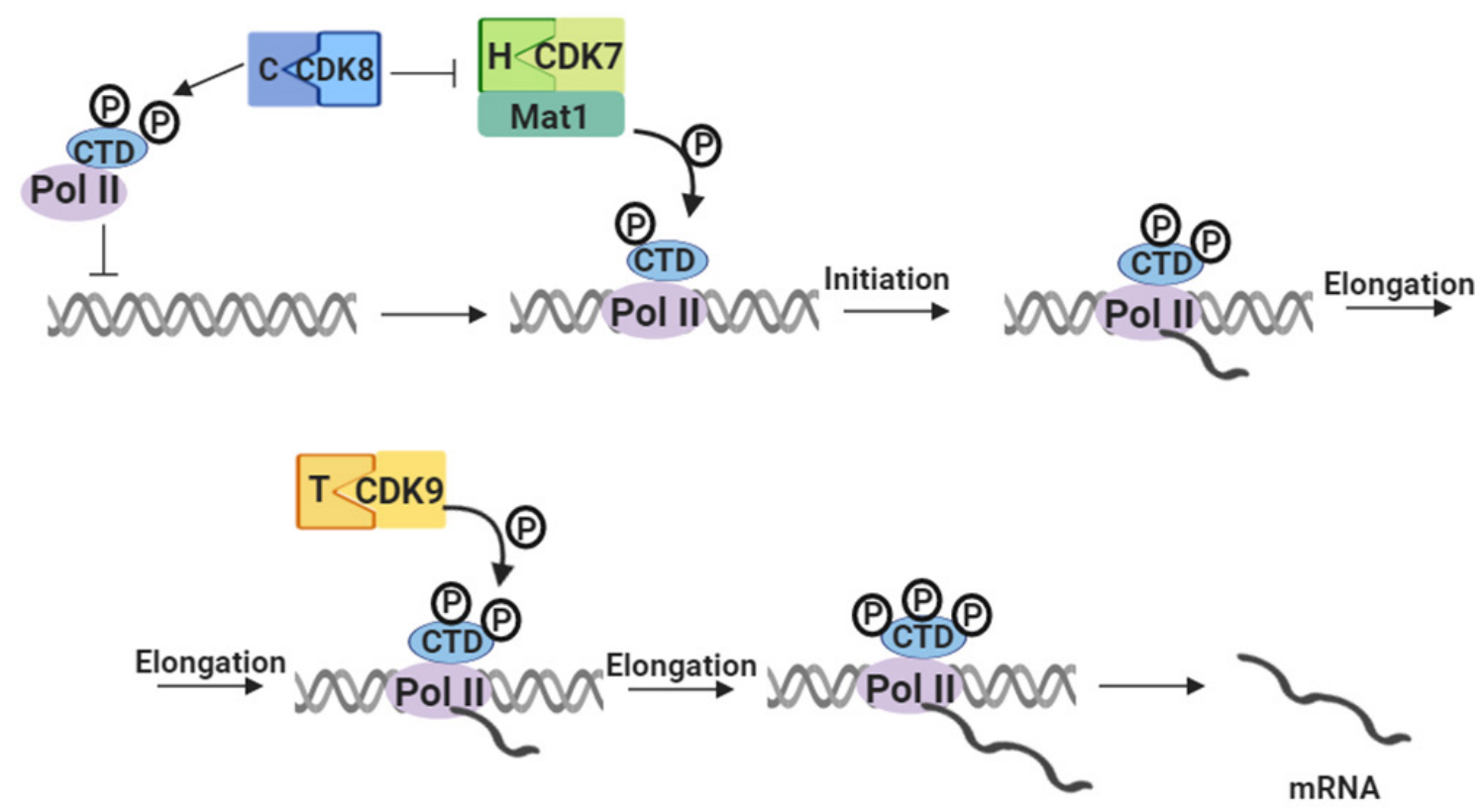

Figure 2. CDKs and their function in RNA Polll transcription. CDKs 7 and 9 are involved in RNA polymerase II activity by directly phosphorylating CTD and thus control the generation of mRNA transcripts. CDK7-CycH-Mat1 complex is under control of CDK8CycC complex, which acts as its inhibitor. CDK8-CycC complex also prevents binding of RNA Polll to promoter DNA region by its phosphorylation. CDK7-CycH-Mat1 complex phosphorylates RNA PollI CTD domain and enables transcription initiation. Further phosphorylation with CDK9-CycT leads to transcription elongation and mRNA production. Single letters stand for cyclins, for instance T is cyclin T. Pol II: RNA polymerase II; P: phosphatidyl group; CDK: cyclin-dependent kinase; CTD: carboxy-terminal domain; mRNA: messenger RNA

After Finn et al..$^{[5]}$ demonstrated synergy between palbociclib and endocrine therapy in luminal oestrogen receptor-positive human breast cancer cell lines, it was first tested in Phase I clinical trials in patients with other solid tumours and non-Hodgkin's lymphoma ${ }^{[80]}$. Palbociclib was well tolerated by patients with advanced solid tumours, with the dose-limiting toxicities mainly related to myelosuppression ${ }^{[80]}$. Palbociclib was next studied in a randomised Phase II clinical trial in metastatic hormone receptor positive breast cancer, in which the combination of palbociclib and endocrine therapy significantly prolonged progression-free survival of patients over endocrine therapy alone ${ }^{[5]}$. Recently, palbociclib has been shown to be effective when combined with fulvestrant in patients with HR+ and human epidermal growth factor receptor 2 negative (HER2-) advanced breast cancer who have stopped responding to endocrine therapy $^{[81]}$. Phase III clinical trials using palbociclib in combination with non-steroid aromatase inhibitor in postmenopausal women with HR+ mBC showed median PFS of 24.8 months compared to 14.5 for placebo treated group ${ }^{[82]}$. Another trial using palbociclib in combination with fulvestrant showed benefits for patients with $\mathrm{HR}+\mathrm{mBC}$ that relapsed or progressed during endocrine therapy ${ }^{[83]}$.

Ribociclib is another highly selective CDK4/6 inhibitor approved for the treatment of HR+ mBC patients. A recent Phase III clinical trial using ribociclib in combination with letrozole in HR+ $\mathrm{mBC}$ showed an increase in PFS in patients: 25 months vs. 16 months compared to placebo group ${ }^{[6]}$. MONALEESA-3 study showed an eight-month improvement in PFS when ribociclib was used in combination with fulvestrant compared to fulvestrant alone ${ }^{[84]}$. Another significant trial including ribociclib, MONALEESA-7, demonstrated improved PFS from 13 to 23.8 months when ribociclib was administrated with tamoxifen/ goserelin or non-steroidal aromatase inhibitor/goserelin compared to placebo ${ }^{[85]}$.

The third approved CKI for $\mathrm{HR}+\mathrm{mBC}$ treatment is abemaciclib. Low $\mathrm{IC}_{50}$ values for CDKs 4 and 6 , ranging from 2 to $10 \mathrm{nM}$, respectively, in addition to CDK 9 inhibition make this CKI most potent in $\mathrm{HR}+\mathrm{mBC}$ 


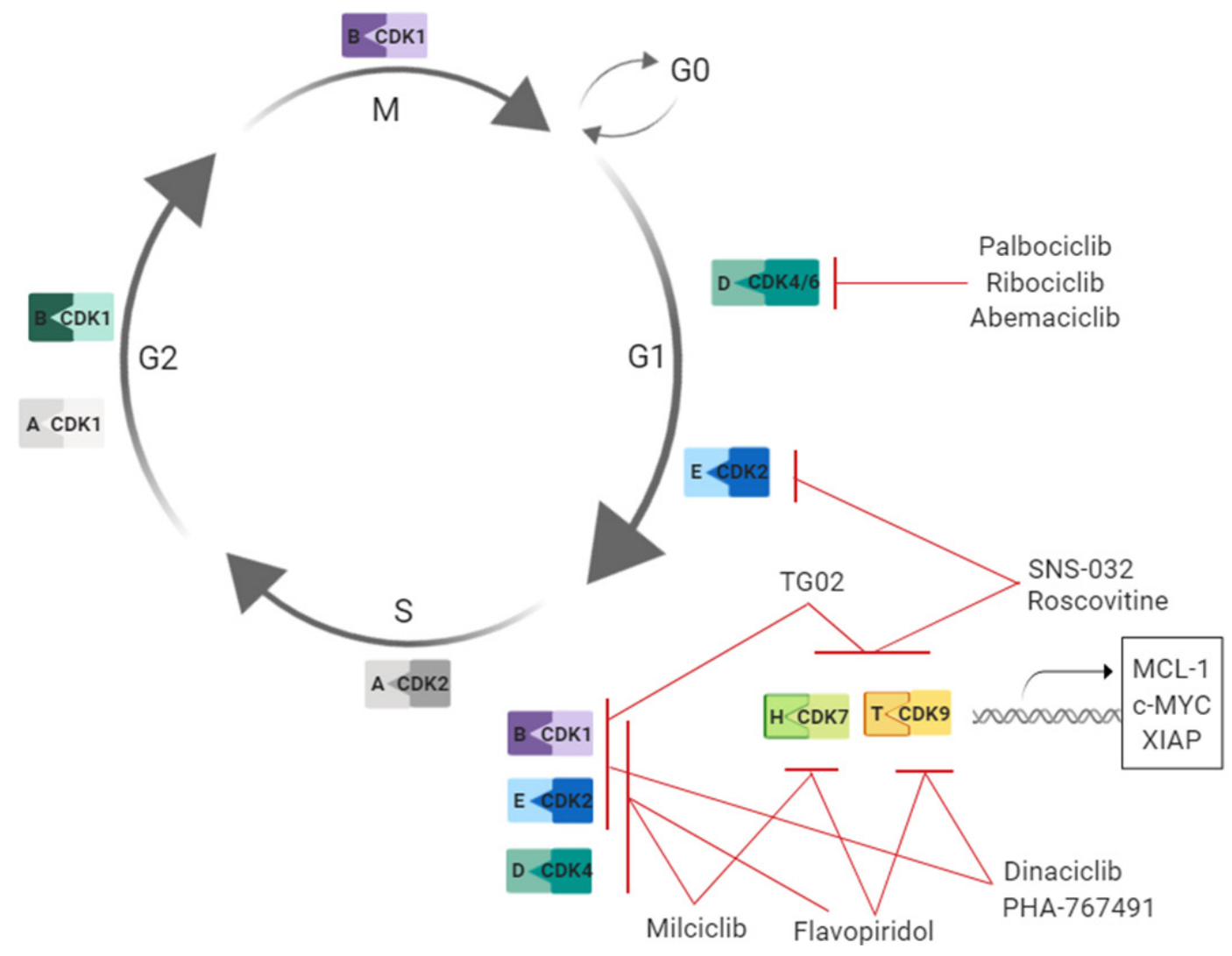

Figure 3. Cell-cycle regulation, CKIs studied in glioma treatment and their targets. Cell-cycle progression in cancer and the role of cyclindependent kinases inhibitors used in glioma studies. CDK2-cyclin E complex phosphorylates Rb leading to loss of repression of E2F factors, resulting in cell-cycle progression. Blocking the CDK2 with CKIs leads to cell-cycle arrest by preventing cell-cycle progression from $\mathrm{G} 1$ to $\mathrm{S}$ phase. Phosphorylation of carboxy-terminal domain of RNAP II by CDK9-cyclin T and CDK7-cyclin H complexes leads to transcription elongation. Blocking of CDKs 9 and 7 leads to transcription inhibition and downregulation of short-lived mRNAs, including MCL-1, c-MYC and XIAP. Single letters stand for cyclins, for instance E is cyclin E. G1: growth phase; S: DNA synthesis; G2: second growth phase; M: mitosis; GO: resting phase; CDK: cyclin-dependent kinase; MCL-1: myeloid leukaemia 1 protein; C-MYC: avian myelocytomatosis virus oncogene cellular homolog; RNAP II: RNA polymerase II; Rb: retinoblastoma protein; XIAP: X-linked inhibior of apoptosis protein; E2F: E2 transcription factor

treatment ${ }^{[86]}$. In combination with either letrozole or anastrozole, abemaciclib significantly improved PFS to 14.7 months $^{[7]}$. When combined with the oestrogen receptor degrader fulvestrant in the MONARCH 2 study, abemaciclib led to PFS improvement, from 9.3 to 16.4 months ${ }^{[87]}$.

\section{CKIs IN GLIOMA TREATMENT - PRECLINICAL STUDIES}

Flavopiridol is one of the most extensively investigated CKIs in the treatment of glioma. Flavopiridol directly inhibits CDKs 1,2 and $4^{[88,89]}$ and induces cell-cycle arrest in G1 or G2 phase [Figure 3]. Additionally, it inhibits $\mathrm{CDK} 7-\mathrm{CycH}$, thus preventing the phosphorylation and subsequent activation of several CDKs involved in the regulation of cell-cycle progression ${ }^{[90]}$. Furthermore, flavopiridol downregulates cyclin D1, the cyclin associated with CDKs 4 and $6{ }^{[91]}$. Promising results were obtained in glioma cell lines when flavopiridol was administered as a single agent ${ }^{[92]}$. In this study, the authors showed that flavopiridol induced caspase-independent cell death in a panel of GBM cell lines independently of p53 and Rb status ${ }^{[92]}$. Newcomb et al.$^{[93]}$ further showed that flavopiridol inhibited the growth of GL261 gliomas in subcutaneous and intracranial models in vivo. Another study showed enhanced cytotoxicity when flavopiridol was combined with TMZ, in both glioma cells in vitro and in nude mice with xenografted U87MG cells ${ }^{[9]}$. However, this first-generation pan-CDK inhibitor failed to enter clinical trials as its low specificity for CDKs resulted in a significant toxicity profile. 
Roscovitine, another pan-CDK inhibitor, was first described by Meijer et al. ${ }^{[94]}$. They demonstrated the drug's ability to inhibit CDKs 1, 2 and 5 [Figure 3]. More recent research has revealed that roscovitine also inhibits CDKs which are not directly involved in the regulation of the cell cycle, namely CDKs 7 and $9^{[95,96]}$. Kolodziej et al.$^{[96]}$ showed anti-tumour effects of roscovitine when administrated as a single agent in the GBM cell lines A172 and G28. Several groups have shown that roscovitine can induce significant levels of apoptosis in GBM cell lines upon co-treatment with the death receptor ligand TNF-related apoptosisinducing ligand (TRAIL) ${ }^{[97,98]}$. Resistance to TRAIL-mediated apoptosis in GBM was overcome by roscovitine's ability to downregulate survivin, XIAP and $\mathrm{Mcl}^{-197,98]}$. More recently, using glioma cell lines and an in vivo orthotopic glioma model, the combination of roscovitine with TMZ was shown to result in increased autophagy and caspase-3 mediated cell death ${ }^{[99]}$. Menn et al ${ }^{[100]}$ showed the ability of roscovitine to cross the $\mathrm{BBB}$ in healthy adult rats while studying ischemic stroke. While roscovitine has not been tested in GBM patients, it is currently in clinical trials for non-small cell lung carcinoma (NCT00372073), rheumatoid arthritis (ISRCTN36667085) and Cushing's disease (NCT03774446).

Milciclib is another CKI developed to target CDKs 2, 7, 4, 5 and 1 [Figure 3]. This CKI was first tested in human ovarian carcinoma cells. Upon demonstration of in vitro effectiveness ${ }^{[101]}$, it entered Phase I and II studies in adult patients with advanced/metastatic solid tumours (NCT01300468). It has been shown that milciclib induces autophagic cell death in a panel of GBM cell lines ${ }^{[102]}$. In this same study, it was shown that milciclib effectively crossed the BBB and reduced tumour size in two in vivo GBM models ${ }^{[102]}$. Milciclib has also shown anti-tumour activity when used in combination with TMZ and RT in a xenograft model of $\mathrm{GBM}^{[102]}$. Overall, these results highlight the potential for future investigations on the applicability of milciclib for the treatment of GBM patients.

Dinaciclib is another inhibitor that targets multiple CDKs ${ }^{[103]}$. Dinaciclib inhibits CDKs 1, 2, 5 and 9 [Figure 3], thus inhibiting CDKs involved in both cell-cycle regulation and transcription ${ }^{[104,105]}$. In vitro studies by Jane and colleagues showed that dinaciclib induced cell-cycle arrest in glioma cells regardless of p53 mutational status ${ }^{[106]}$. Although antiproliferative effects were present, there was no evidence of cell death when dinaciclib was used as a single agent ${ }^{[106]}$. In combination with the Bcl-2 and Bcl-xL inhibitor ABT-737, dinaciclib induced apoptotic cell death in glioma cells, while further mechanistic investigations showed that the observed cell death was a consequence of Mcl-1 downregulation ${ }^{[106]}$. Dinaciclib has a lower toxicity profile compared to other pan-CKIs but the exact reasons behind this are still unknown. It could be due to more specific targeting of CDKs compared to other pan-CKIs or due to having fewer non-CDK off-target effects $^{[107]}$. As a result of lower toxicity profile, dinaciclib has entered clinical trials and is currently in Phase III trial for refractory chronic lymphocytic leukaemia (NCT01580228) and the results from this trial are eagerly anticipated.

SNS-032 is a potent CKI that inhibits both the cell cycle via CDKs 2 and 7 and transcription via CDKs 7 and 9 [Figure 3]. SNS-032 was shown to be effective in GBM cell lines, where it inhibited cellular proliferation in a dose-dependent manner ${ }^{[108]}$, by blocking the production of vascular endothelial growth factor. Ali et al ${ }^{[109]}$ additionally showed that SNS-032 prevented hypoxia-mediated U87MG cell invasion, via its ability to interfere with the expression of HIF-1 $\alpha$ and its trans-regulating factors. SNS-032 was also tested in lymphocytic leukaemia where Chen et al. ${ }^{[110]}$, showed the ability of SNS-032 to downregulate the anti-apoptotic protein Mcl-1 and induce apoptotic cell death, to a much higher extent when compared to flavopiridol and roscovitine. These results led to a clinical study using SNS-032 in chronic lymphocytic leukaemia and multiple myeloma (NCT00446342) ${ }^{[111]}$. The results from this clinical study remain unpublished.

Erbayraktar et al. ${ }^{[112]}$ used the cell division cycle 7-related protein kinase (Cdc7) inhibitor PHA-767491 to enhance replicative stress in glioblastoma cells. They showed that Cdc7 inhibition resulted in inhibition of 
Table 2. CKIs used in glioma preclinical studies

\begin{tabular}{|c|c|c|c|c|}
\hline CKI drugs & Targets & Combination with other drugs & BBB penetration & Ref. \\
\hline \multirow[t]{5}{*}{ Flavopiridol (alvocidib) } & CDK $1,2,4,9,7$ & Not reported & Yes & {$[92]$} \\
\hline & & Not reported & & [113] \\
\hline & & Not reported & & {$[93]$} \\
\hline & & Temozolomide & & [9] \\
\hline & & Not reported & & {$[91]$} \\
\hline \multirow[t]{4}{*}{ Roscovitine (Seliciclib, CYC202) } & $\operatorname{CDK} 2,5,7,9$ & TRAIL & Yes & {$[97]$} \\
\hline & & TRAIL & & [98] \\
\hline & & Not reported & & {$[96]$} \\
\hline & & Temozolomide & & {$[99]$} \\
\hline Milciclib (PHA-848125) & $\operatorname{CDK} 2,4,7,1$ & Temozolomide & Yes & [102] \\
\hline Dinaciclib (SCH727965, MK-7965) & $\operatorname{CDK} 2,5,1,9$ & ABT-737 & Not reported & [106] \\
\hline \multirow[t]{2}{*}{ SNS-032 (BMS-387032) } & $\operatorname{CDK} 2,7,9$ & Not reported & Not reported & [108] \\
\hline & & Celecoxib, SU 5416 and GM 6001 & & [109] \\
\hline PHA-767491 & Cdc7; CDK 9, 2, 1 & Not reported & Not reported & {$[112]$} \\
\hline
\end{tabular}

CKIs: cyclin-dependent kinase inhibitors; CDK: cyclin-dependent kinase; BBB: blood-brain barrier; TRAIL: TNF-related apoptosis-inducing ligand; Cdc7: cell division cycle 7-related protein kinase

cellular proliferation, apoptotic cell death induction and blocked GBM invasiveness. PHA-767491 is a firstgeneration $\mathrm{Cdc7}$ inhibitor with well described anti-tumour activity and more improvement in this field is expected.

Table 2 summarises CKIs used in glioma preclinical studies either as a single treatment or in combination with TMZ/other drugs.

\section{CKIs REACHED CLINICAL STUDIES IN GLIOMA}

After being extensively investigated in different types of cancer and clinically approved for patients with $\mathrm{ER}+\mathrm{mBC}$, palbociclib entered studies for glioma treatment. Initial results showed promise, with palbociclib being able to penetrate the $\mathrm{BBB}$ and reduce tumour growth in glioblastoma intracranial xenografts ${ }^{[114]}$. Palbociclib was also shown to be effective in vitro and in vivo as a single treatment and in combination with GBM standard of care, radiotherapy and $\mathrm{TMZ}^{[114]}$. A recent publication showed the potential of palbociclib combined with RT in patient-derived glioblastoma cell lines ${ }^{[15]}$. Despite these promising results obtained in preclinical studies, palbociclib was inefficient when tested as a monotherapy in a Phase II clinical trial for recurrent GBM patients with detectable Rb expression (NCT01227434) ${ }^{[11]}$. More recently, a clinical trial examining the effectiveness of palbociclib in anaplastic oligodendrogliomas was stopped early due to lack of efficacy, with $74 \%$ of evaluable patients progressing within six months, despite good drug tolerance and exposure $^{[116]}$. Among the many on-going or terminated clinical trials using palbociclib in glioma treatment, these are the only studies with published results while findings from other clinical studies are highly anticipated.

Ribociclib, an orally bioavailable CDK4/6 inhibitor [Figure 3], is currently under investigation for the treatment of paediatric CNS tumours ${ }^{[117]}$. Initially tested was ribociclib's ability to reach its targets in the brain. This characteristic was tested in both non-tumour bearing mice and in mice bearing DIPGx7 (glioma) cortical allograft tumours ${ }^{[117]}$. Ribociclib was shown to have adequate CNS exposure and will be further investigated as a treatment option for childhood brain tumours. However, a recent study showed that the brain penetrance of ribociclib in vivo is restricted by the $\mathrm{ABCB} 1$ transporter ${ }^{[118]}$, leading to the suggestion that co-administration of the $\mathrm{ABCB} 1$ inhibitor elacridar could dramatically improve the brain penetrance of ribociclib ${ }^{[118]}$ and further investigations are underway. A clinical trial testing ribociclib in recurrent GBM patients showed that ribociclib can cross the tumour-brain barrier at pharmacologically-active 
Table 3. CKIs used in glioma clinical studies

\begin{tabular}{|c|c|c|c|c|c|}
\hline CKI drugs & Targets & $\begin{array}{c}\text { Clinical trial } \\
\text { phase }\end{array}$ & Glioma grade & $\begin{array}{c}\text { Combination with other } \\
\text { drugs/radiotherapy }\end{array}$ & $\begin{array}{c}\text { ClinicalTrials.gov } \\
\text { identifier }\end{array}$ \\
\hline \multirow{6}{*}{$\begin{array}{l}\text { Abemaciclib } \\
\text { (LY2835219, } \\
\text { Verzenio) }\end{array}$} & \multirow[t]{6}{*}{ CDK 4, 6} & Phase II & Recurrent glioblastoma & No & NCT02981940 \\
\hline & & Phase II & Glioblastoma & Temozolomide & NCT02977780 \\
\hline & & Phase II & Recurrent glioblastoma & Bevacizumab & NCT04074785 \\
\hline & & Phase II & Recurrent glioblastoma & No & NCT03220646 \\
\hline & & Phase I & Recurrent brain tumour & No & NCT02644460 \\
\hline & & Phase II & Oligodendroglioma & No & NCT03969706 \\
\hline \multirow[t]{4}{*}{$\begin{array}{l}\text { Ribociclib } \\
\text { (Kisqali) }\end{array}$} & \multirow[t]{4}{*}{ CDK 4,6} & Phase I & $\begin{array}{l}\text { Recurrent glioblastoma/anaplastic } \\
\text { glioma }\end{array}$ & No & NCT02345824 \\
\hline & & Phase I & Glioma/Meningioma & No & NCT02933736 \\
\hline & & Phase I & Paediatric gliomas/HGG & Everolimus/Radiotherapy & NCT03355794 \\
\hline & & Phase I & Recurrent brain tumours & $\begin{array}{l}\text { Gemcitabine, sonidegib, } \\
\text { trametinib }\end{array}$ & NCT03434262 \\
\hline \multirow{8}{*}{$\begin{array}{l}\text { Palbociclib (PD- } \\
\text { 0332991) }\end{array}$} & \multirow[t]{8}{*}{ CDK 4,6} & Phase II & Oligodendroglioma/Oligoastrocytoma & No & NCT02530320 \\
\hline & & Phase I & Central nervous system tumours & No & NCT02255461 \\
\hline & & Phase II & $\begin{array}{l}\text { Recurrent glioblastoma/gliosarcoma/ } \\
\text { anaplastic astrocytoma }\end{array}$ & No & NCT01227434 \\
\hline & & $\begin{array}{l}\text { Phase I/ } \\
\text { Phase II }\end{array}$ & Glioblastoma & Radiotherapy & NCT03158389 \\
\hline & & Phase II & Glioma & No & NCT02465060 \\
\hline & & Phase II & $\begin{array}{l}\text { Recurrent childhood } \\
\text { Medulloblastoma/Malignant glioma }\end{array}$ & No & NCT03155620 \\
\hline & & Phase II & $\begin{array}{l}\text { Recurrent malignant glioma/recurrent } \\
\text { medulloblastoma }\end{array}$ & No & NCT03526250 \\
\hline & & Phase I & Medulloblastoma & Temozolomide, irinotecan & NCT03709680 \\
\hline \multirow[t]{2}{*}{ TG02 (SB1317) } & \multirow[t]{2}{*}{$\begin{array}{l}\text { CDK 1, 2, 5, } \\
7,9\end{array}$} & $\begin{array}{l}\text { Phase I/ } \\
\text { Phase II }\end{array}$ & $\begin{array}{l}\text { Recurrent anaplastic astrocytoma/ } \\
\text { glioblastoma }\end{array}$ & Temozolomide & NCT02942264 \\
\hline & & Phase I & Astrocytoma, Grade III glioblastoma & Temozolomide, radiotherapy & NCT03224104 \\
\hline
\end{tabular}

HGG: high-grade glioma; CKIs: cyclin-dependent kinase inhibitors; CDK: cyclin-dependent kinase

concentrations and suppress tumour proliferation. This Phase II study suggested however that ribociclib is ineffective as a monotherapy, and proposed that the addition of an mTOR inhibitor may be a viable dualdrug strategy for recurrent glioblastoma ${ }^{[119]}$.

Raub et al ${ }^{[120]}$ used in vivo glioblastoma models to assess the anti-tumour activity of abemaciclib, while also comparing it to palbociclib. They showed that abemaciclib has anti-tumour activity in intracranial glioblastoma xenograft models, as survival times of tumour-bearing rats increased upon abemaciclib administration ${ }^{[120]}$. More importantly, additive or greater than additive effects were noted when abemaciclib was combined with $\mathrm{TMZ}^{[120]}$. In the same study, they showed that abemaciclib crosses the BBB more readily when compared to palbociclib ${ }^{[120]}$, giving hope for its future exploitation in clinical settings for glioma treatment.

Further adding to abemaciclib's potential as a future therapy for brain tumour patients is its ability to cross the $\mathrm{BBB}$, as demonstrated in a study examining its benefit as a treatment for patients with brain metastases (BM) secondary to breast cancer ${ }^{[121]}$. A clinical trial testing abemaciclib in patients with BM is now closed and results are anticipated (NCT02308020).

TG02 is a brain-penetrating multi-CDK inhibitor ${ }^{[122]}$ [Figure 3]. A recent study showed that TG02 decreased cell viability by targeting CDK9 in patient-derived GBM cells and inhibited tumour growth in an intracranial GBM mouse model ${ }^{[122]}$. TG02 also inhibited cell proliferation and induced cell death in a CDK9 expression-dependent manner in panel of GBM cell lines ${ }^{[123]}$. Additionally, synergism was observed when TG02 was combined with TMZ in cell lines and syngeneic mouse orthotopic GBM model ${ }^{[123]}$. Another group also showed that TG02 reduced cell viability in a panel of GBM cell lines ${ }^{[124]}$, independent 
of MGMT promoter methylation status. These findings resulted in an on-going clinical trial examining the effectiveness of TG02 in combination with temozolomide in patients with recurrent anaplastic astrocytoma and glioblastoma (NCT02942264). Even though final results are not published, promising results from the Phase I trial have recently been reported, showing that TG02 administration at the maximal tolerated dose and in combination with TMZ has a tolerable toxicity profile ${ }^{[125]}$. A second clinical trial using TG02 in combination with either RT or TMZ, in newly diagnosed elderly glioblastoma or anaplastic astrocytoma patients, is also on-going (NCT03224104). Final outcomes of both trials are eagerly awaited.

The on-going or completed clinical trials using CKIs either as a single treatment or in combination with other drugs or radiotherapy are given in Table 3.

A schematic figure summarising CKIs used in preclinical and clinical studies in gliomas is shown in Figure 3.

\section{CONCLUSION}

The location of brain tumours and their protection by the BBB means that brain tumours remain the most challenging malignancies to treat. Amongst these, GBM is the most deadly. New treatment approaches are needed that cross the $\mathrm{BBB}$, specifically target the tumour cells and are relatively non-toxic to normal brain cells. CKIs display such attributes and their potential as a novel treatment approach for GBM patients has been supported by multiple preclinical studies. However, similar strong preclinical evidence supported the potential of CDK4/6 inhibition in breast cancer treatment for many years, yet specific and efficient CKIs of CDK4/6 only became recently available. As results from on-going clinical trials emerge and further preclinical studies are conducted, it is hoped that the potential of CDK inhibitors in the treatment of brain tumours, especially GBM, will soon be realised for the benefit of all brain tumour patients.

\section{DECLARATIONS}

\section{Authors' contributions}

Authors equally contributed to this paper with regard to conception and design of the study, literature review and analysis, drafting and critical revision and editing, and final approval of the final version.

\section{Availability of data and materials}

Not applicable.

\section{Financial support and sponsorship}

This work was supported by the European Union's Horizon 2020 research and innovation programme under the Marie Skłodowska-Curie grant agreement \#766069 (GLIO-TRAIN).

\section{Conflicts of interest}

All authors declared that there are no conflicts of interest.

\section{Ethical approval and consent to participate}

Not applicable.

\section{Consent for publication}

Not applicable.

\section{Copyright}

(c) The Author(s) 2020. 


\section{REFERENCES}

1. Graña X, Reddy EP. Cell cycle control in mammalian cells: role of cyclins, cyclin dependent kinases (CDKs), growth suppressor genes and cyclin-dependent kinase inhibitors (CKIs). Oncogene 1995;11:211-9.

2. Malumbres M, Barbacid M. To cycle or not to cycle: a critical decision in cancer. Nat Rev Cancer 2001;1:222-31.

3. Malumbres M, Barbacid M. Cell cycle, CDKs and cancer: a changing paradigm. Nat Rev Cancer 2009;9:153-66.

4. Hanahan D, Weinberg RA. Hallmarks of cancer: the next generation. Cell 2011;144:646-74.

5. Finn RS, Dering J, Conklin D, Kalous O, Cohen DJ, et al. PD 0332991, a selective cyclin D kinase 4/6 inhibitor, preferentially inhibits proliferation of luminal estrogen receptor-positive human breast cancer cell lines in vitro. Breast Cancer Res 2009;11:R77.

6. Hortobagyi GN, Stemmer SM, Burris HA, Yap YS, Sonke GS, et al. Ribociclib as first-line therapy for HR-positive, advanced breast cancer. N Engl J Med 2016;375:1738-48.

7. Goetz MP, Toi M, Campone M, Sohn J, Paluch-Shimon S, et al. MONARCH 3: abemaciclib as initial therapy for advanced breast cancer. J Clin Oncol 2017;35:3638-46.

8. Crespo I, Vital AL, Gonzalez-Tablas M, Patino MdC, Otero A, et al. Molecular and genomic alterations in glioblastoma multiforme. Am J Pathol 2015;185:1820-33.

9. Hayashi T, Adachi K, Ohba S, Hirose Y. The Cdk inhibitor flavopiridol enhances temozolomide-induced cytotoxicity in human glioma cells. J Neurooncol 2013;115:169-78.

10. Bose P, Simmons GL, Grant S. Cyclin-dependent kinase inhibitor therapy for hematologic malignancies. Expert Opin Investig Drugs 2013;22:723-38.

11. Taylor JW, Parikh M, Phillips JJ, James CD, Molinaro AM, et al. Phase-2 trial of palbociclib in adult patients with recurrent RB1positive glioblastoma. J Neurooncol 2018;140:477-83.

12. Kleihues P, Burger PC, Scheithauer BW. The new WHO classification of brain tumours. Brain Pathol 1993;3:255-68.

13. Louis DN, Ohgaki H, Wiestler OD, Cavenee WK, Burger PC, et al. The 2007 WHO classification of tumours of the central nervous system. Acta Neuropathol 2007;114:97-109.

14. Karcher S, Steiner HH, Ahmadi R, Zoubaa S, Vasvari G, et al. Different angiogenic phenotypes in primary and secondary glioblastomas. Int J Cancer 2006;118:2182-9.

15. Kleihues P, Ohgaki H. Primary and secondary glioblastomas: from concept to clinical diagnosis. Neuro Oncol 1999;1:44-51.

16. Li R, Li H, Yan W, Yang P, Bao Z, et al. Genetic and clinical characteristics of primary and secondary glioblastoma is associated with differential molecular subtype distribution. Oncotarget 2015;6:7318-24.

17. Korshunov A, Sycheva R, Golanov A. Genetically distinct and clinically relevant subtypes of glioblastoma defined by array-based comparative genomic hybridization (array-CGH). Acta Neuropathol 2006;111:465-74.

18. Morokoff A, Ng W, Gogos A, Kaye AH. Molecular subtypes, stem cells and heterogeneity: implications for personalised therapy in glioma. J Clin Neurosci 2015;22:1219-26.

19. Ohgaki H, Kleihues P. The definition of primary and secondary glioblastoma. Clin Cancer Res 2013;19:764-72.

20. Verhaak RG, Hoadley KA, Purdom E, Wang V, Qi Y, et al. Integrated genomic analysis identifies clinically relevant subtypes of glioblastoma characterized by abnormalities in PDGFRA, IDH1, EGFR, and NF1. Cancer Cell 2010;17:98-110.

21. Cooper LA, Gutman DA, Long Q, Johnson BA, Cholleti SR, et al. The proneural molecular signature is enriched in oligodendrogliomas and predicts improved survival among diffuse gliomas. PLoS One 2010;5:e12548.

22. Ducray F, Idbaih A, de Reynies A, Bieche I, Thillet J, et al. Anaplastic oligodendrogliomas with 1p19q codeletion have a proneural gene expression profile. Mol Cancer 2008;7:41.

23. Johnson BE, Mazor T, Hong C, Barnes M, Aihara K, et al. Mutational analysis reveals the origin and therapy-driven evolution of recurrent glioma. Science 2014;343:189-93.

24. Phillips HS, Kharbanda S, Chen R, Forrest WF, Soriano RH, et al. Molecular subclasses of high-grade glioma predict prognosis, delineate a pattern of disease progression, and resemble stages in neurogenesis. Cancer Cell 2006;9:157-73.

25. Network CGAR. Comprehensive genomic characterization defines human glioblastoma genes and core pathways. Nature 2008;455:1061-8.

26. Wang Q, Hu B, Hu X, Kim H, Squatrito M, et al. Tumor evolution of glioma-intrinsic gene expression subtypes associates with immunological changes in the microenvironment. Cancer Cell 2017;32:42-56.e6.

27. Hegi ME, Diserens AC, Gorlia T, Hamou MF, de Tribolet N, et al. MGMT gene silencing and benefit from temozolomide in glioblastoma. N Engl J Med 2005;352:997-1003.

28. Stupp R, Mason WP, van den Bent MJ, Weller M, Fisher B, et al. Radiotherapy plus concomitant and adjuvant temozolomide for glioblastoma. N Engl J Med 2005;352:987-96.

29. Quiros S, Roos WP, Kaina B. Processing of O6-methylguanine into DNA double-strand breaks requires two rounds of replication whereas apoptosis is also induced in subsequent cell cycles. Cell Cycle 2010;9:168-78.

30. Murphy AC, Weyhenmeyer B, Schmid J, Kilbride SM, Rehm M, et al. Activation of executioner caspases is a predictor of progressionfree survival in glioblastoma patients: a systems medicine approach. Cell Death Dis 2013;4:e629.

31. Mirimanoff RO, Gorlia T, Mason W, Van den Bent MJ, Kortmann RD, et al. Radiotherapy and temozolomide for newly diagnosed glioblastoma: recursive partitioning analysis of the EORTC 26981/22981-NCIC CE3 phase III randomized trial. J Clin Oncol 2006;24:2563-9.

32. Cai X, Sughrue ME. Glioblastoma: new therapeutic strategies to address cellular and genomic complexity. Oncotarget 2018;9:9540-54.

33. Upadhyay RK. Drug delivery systems, CNS protection, and the blood brain barrier. Biomed Res Int 2014;2014:869269. 
34. Fulda S, Debatin KM. Extrinsic versus intrinsic apoptosis pathways in anticancer chemotherapy. Oncogene 2006;25:4798-811.

35. Donson AM, Addo-Yobo SO, Handler MH, Gore L, Foreman NK. MGMT promoter methylation correlates with survival benefit and sensitivity to temozolomide in pediatric glioblastoma. Pediatr Blood Cancer 2007;48:403-7.

36. Ruano Y, Mollejo M, Camacho FI, Rodriguez de Lope A, Fiano C, et al. Identification of survival-related genes of the phosphatidylinositol 3'-kinase signaling pathway in glioblastoma multiforme. Cancer 2008;112:1575-84.

37. Strik H, Deininger M, Streffer J, Grote E, Wickboldt J, et al. BCL-2 family protein expression in initial and recurrent glioblastomas: modulation by radiochemotherapy. J Neurol Neurosurg Psychiatry 1999;67:763-8.

38. Fulda S. Molecular pathways: targeting inhibitor of apoptosis proteins in cancer--from molecular mechanism to therapeutic application. Clin Cancer Res 2014;20:289-95.

39. Hsieh P, Yamane K. DNA mismatch repair: molecular mechanism, cancer, and ageing. Mech Ageing Dev 2008;129:391-407.

40. Russell P, Nurse P. cde25+ functions as an inducer in the mitotic control of fission yeast. Cell 1986;45:145-53.

41. Draetta G, Brizuela L, Potashkin J, Beach D. Identification of p34 and p13, human homologs of the cell cycle regulators of fission yeast encoded by cde2+ and suc1+. Cell 1987;50:319-25.

42. Sherr CJ. Cancer cell cycles. Science 1996;274:1672-7.

43. Nurse P, Masui Y, Hartwell L. Understanding the cell cycle. Nat Med 1998;4:1103-6.

44. Chen YJ, Dominguez-Brauer C, Wang Z, Asara JM, Costa RH, et al. A conserved phosphorylation site within the forkhead domain of FoxM1B is required for its activation by cyclin-CDK1. J Biol Chem 2009;284:30695-707.

45. Marais A, Ji Z, Child ES, Krause E, Mann DJ, et al. Cell cycle-dependent regulation of the forkhead transcription factor FOXK2 by CDK.cyclin complexes. J Biol Chem 2010;285:35728-39.

46. Tomashevski A, Webster DR, Grammas P, Gorospe M, Kruman, II. Cyclin-C-dependent cell-cycle entry is required for activation of non-homologous end joining DNA repair in postmitotic neurons. Cell Death Differ 2010;17:1189-98.

47. Aggarwal P, Vaites LP, Kim JK, Mellert H, Gurung B, et al. Nuclear cyclin D1/CDK4 kinase regulates CUL4 expression and triggers neoplastic growth via activation of the PRMT5 methyltransferase. Cancer Cell 2010;18:329-40.

48. Dickinson LA, Edgar AJ, Ehley J, Gottesfeld JM. Cyclin L is an RS domain protein involved in pre-mRNA splicing. J Biol Chem 2002;277:25465-73.

49. Loyer P, Trembley JH, Grenet JA, Busson A, Corlu A, et al. Characterization of cyclin L1 and L2 interactions with CDK11 and splicing factors: influence of cyclin L isoforms on splice site selection. J Biol Chem 2008;283:7721-32.

50. Lam PY, Di Tomaso E, Ng HK, Pang JC, Roussel MF, et al. Expression of p19INK4d, CDK4, CDK6 in glioblastoma multiforme. Br J Neurosurg 2000;14:28-32.

51. Ye X, Zhu C, Harper JW. A premature-termination mutation in the Mus musculus cyclin-dependent kinase 3 gene. Proc Natl Acad Sci U S A 2001;98:1682-6.

52. Patrick GN, Zukerberg L, Nikolic M, de la Monte S, Dikkes P, et al. Conversion of p35 to p25 deregulates Cdk5 activity and promotes neurodegeneration. Nature 1999;402:615-22.

53. Shupp A, Casimiro MC, Pestell RG. Biological functions of CDK5 and potential CDK5 targeted clinical treatments. Oncotarget 2017;8:17373-82.

54. Hagmann H, Taniguchi Y, Pippin JW, Kauerz HM, Benzing T, et al. Cyclin I and p35 determine the subcellular distribution of Cdk5. Am J Physiol Cell Physiol 2015;308:C339-47.

55. Harper JW, Elledge SJ. The role of Cdk7 in CAK function, a retro-retrospective. Genes Dev 1998;12:285-9.

56. Serizawa H, Makela TP, Conaway JW, Conaway RC, Weinberg RA, et al. Association of Cdk-activating kinase subunits with transcription factor TFIIH. Nature 1995;374:280-2.

57. Shiekhattar R, Mermelstein F, Fisher RP, Drapkin R, Dynlacht B, et al. Cdk-activating kinase complex is a component of human transcription factor TFIIH. Nature 1995;374:283-7.

58. Hengartner CJ, Myer VE, Liao SM, Wilson CJ, Koh SS, et al. Temporal regulation of RNA polymerase II by Srb10 and Kin28 cyclindependent kinases. Mol Cell 1998;2:43-53.

59. Rickert P, Corden JL, Lees E. Cyclin C/CDK8 and cyclin H/CDK7/p36 are biochemically distinct CTD kinases. Oncogene 1999;18:1093.

60. Morgan DO. Cyclin-dependent kinases: engines, clocks, and microprocessors. Annu Rev Cell Dev Biol 1997;13:261-91.

61. Kasten M, Giordano A. Cdk10, a Cdc2-related kinase, associates with the Ets2 transcription factor and modulates its transactivation activity. Oncogene 2001;20:1832-8.

62. Yu DS, Zhao R, Hsu EL, Cayer J, Ye F, et al. Cyclin-dependent kinase 9-cyclin K functions in the replication stress response. EMBO Rep 2010;11:876-82.

63. Bagella L, Giacinti C, Simone C, Giordano A. Identification of murine cdk10: association with Ets2 transcription factor and effects on the cell cycle. J Cell Biochem 2006;99:978-85.

64. Boyer MJ, Cheng T. The CDK inhibitors: potential targets for therapeutic stem cell manipulations? Gene Therapy 2008;15:117-25.

65. Roussel MF. The INK4 family of cell cycle inhibitors in cancer. Oncogene 1999;18:5311-7.

66. Marques-Torrejon MA, Porlan E, Banito A, Gomez-Ibarlucea E, Lopez-Contreras AJ, et al. Cyclin-dependent kinase inhibitor p21 controls adult neural stem cell expansion by regulating Sox2 gene expression. Cell Stem Cell 2013;12:88-100.

67. Pippa R, Espinosa L, Gundem G, Garcia-Escudero R, Dominguez A, et al. p27Kip1 represses transcription by direct interaction with p130/E2F4 at the promoters of target genes. Oncogene 2012;31:4207-20.

68. Li H, Collado M, Villasante A, Matheu A, Lynch CJ, et al. p27(Kip1) directly represses Sox2 during embryonic stem cell 
differentiation. Cell Stem Cell 2012;11:845-52.

69. Akiyama T, Ohuchi T, Sumida S, Matsumoto K, Toyoshima K. Phosphorylation of the retinoblastoma protein by cdk2. Proc Natl Acad Sci U S A 1992;89:7900-4.

70. Chung J, Cho JW, Baek WK, Suh SI, Kwon TK, et al. Expression of RB C pocket fragments in HSF induces delayed cell cycle progression and sensitizes to apoptosis upon cellular stresses. Cell Prolif 2002;35:247-56.

71. Wu CL, Zukerberg LR, Ngwu C, Harlow E, Lees JA. In vivo association of E2F and DP family proteins. Mol Cell Biol 1995;15:2536-46.

72. Munger K, Howley PM. Human papillomavirus immortalization and transformation functions. Virus Res 2002;89:213-28.

73. Brugarolas J, Moberg K, Boyd SD, Taya Y, Jacks T, et al. Inhibition of cyclin-dependent kinase 2 by p21 is necessary for retinoblastoma protein-mediated G1 arrest after gamma-irradiation. Proc Natl Acad Sci U S A 1999;96:1002-7.

74. Zhu X, Ohtsubo M, Bohmer RM, Roberts JM, Assoian RK. Adhesion-dependent cell cycle progression linked to the expression of cyclin D1, activation of cyclin E-cdk2, and phosphorylation of the retinoblastoma protein. J Cell Biol 1996;133:391-403.

75. Lim S, Kaldis P. Cdks, cyclins and CKIs: roles beyond cell cycle regulation. Development 2013;140:3079-93.

76. Bregman DB, Pestell RG, Kidd VJ. Cell cycle regulation and RNA polymerase II. Front Biosci 2000;5:D244-57.

77. Nemet J, Jelicic B, Rubelj I, Sopta M. The two faces of Cdk8, a positive/negative regulator of transcription. Biochimie 2014;97:22-7.

78. Garriga J, Grana X. Cellular control of gene expression by T-type cyclin/CDK9 complexes. Gene 2004;337:15-23.

79. Asghar U, Witkiewicz AK, Turner NC, Knudsen ES. The history and future of targeting cyclin-dependent kinases in cancer therapy. Nat Rev Drug Discov 2015;14:130-46.

80. Schwartz GK, LoRusso PM, Dickson MA, Randolph SS, Shaik MN, et al. Phase I study of PD 0332991, a cyclin-dependent kinase inhibitor, administered in 3-week cycles (Schedule 2/1). Br J Cancer 2011;104:1862-8.

81. Murphy C, Dickler M. The role of CDK4/6 inhibition in breast cancer. Oncologist 2015;20:483-490.

82. Finn R, Martin M, Rugo H, Jones S, Im SA, et al. PALOMA-2: primary results from a phase III trial of palbociclib (P) with letrozole (L) compared with letrozole alone in postmenopausal women with ER+/HER2- advanced breast cancer (ABC). J Clin Oncol 2016;34:507.

83. Cristofanilli M, Turner NC, Bondarenko I, Ro J, Im SA, et al. Fulvestrant plus palbociclib versus fulvestrant plus placebo for treatment of hormone-receptor-positive, HER2-negative metastatic breast cancer that progressed on previous endocrine therapy (PALOMA-3): final analysis of the multicentre, double-blind, phase 3 randomised controlled trial. Lancet Oncol 2016;17:425-39.

84. Slamon DJ, Neven P, Chia S, Fasching PA, De Laurentiis M, et al. Phase III randomized study of ribociclib and fulvestrant in hormone receptor-positive, human epidermal growth factor receptor 2-negative advanced breast cancer: MONALEESA-3. J Clin Oncol 2018;36:2465-72.

85. Tripathy D, Im SA, Colleoni M, Franke F, Bardia A, et al. Ribociclib plus endocrine therapy for premenopausal women with hormonereceptor-positive, advanced breast cancer (MONALEESA-7): a randomised phase 3 trial. Lancet Oncol 2018;19:904-15.

86. Gelbert LM, Cai S, Lin X, Sanchez-Martinez C, Del Prado M, et al. Preclinical characterization of the CDK4/6 inhibitor LY2835219: invivo cell cycle-dependent/independent anti-tumor activities alone/in combination with gemcitabine. Invest New Drugs 2014;32:825-37.

87. Sledge GW Jr, Toi M, Neven P, Sohn J, Inoue K, et al. MONARCH 2: abemaciclib in combination with fulvestrant in women with HR+/HER2- advanced breast cancer who had progressed while receiving endocrine therapy. J Clin Oncol 2017;35:2875-84.

88. Carlson BA, Dubay MM, Sausville EA, Brizuela L, Worland PJ. Flavopiridol induces G1 arrest with inhibition of cyclin-dependent kinase (CDK) 2 and CDK4 in human breast carcinoma cells. Cancer Res 1996;56:2973-8.

89. Losiewicz MD, Carlson BA, Kaur G, Sausville EA, Worland PJ. Potent inhibition of CDC2 kinase activity by the flavonoid L86-8275. Biochem Biophys Res Commun 1994;201:589-95.

90. Caracciolo V, Laurenti G, Romano G, Carnevale V, Cimini AM, et al. Flavopiridol induces phosphorylation of AKT in a human glioblastoma cell line, in contrast to siRNA-mediated silencing of Cdk9: Implications for drug design and development. Cell Cycle 2012;11:1202-16.

91. Cobanoglu G, Turacli I, Ozkan A, Ekmekci A. Flavopiridol's antiproliferative effects in glioblastoma multiforme. J Cancer Res Ther 2016;12:811-7.

92. Alonso M, Tamasdan C, Miller DC, Newcomb EW. Flavopiridol induces apoptosis in glioma cell lines independent of retinoblastoma and 53 tumor suppressor pathway alterations by a caspase-independent pathway. Mol Cancer Ther 2003;2:139-50.

93. Newcomb EW, Tamasdan C, Entzminger Y, Arena E, Schnee T, et al. Flavopiridol inhibits the growth of GL261 gliomas in vivo: implications for malignant glioma therapy. Cell Cycle 2004;3:230-4.

94. Meijer L, Borgne A, Mulner O, Chong JP, Blow JJ, et al. Biochemical and cellular effects of roscovitine, a potent and selective inhibitor of the cyclin-dependent kinases cdc2, cdk2 and cdk5. Eur J Biochem 1997;243:527-36.

95. Leitch AE, Lucas CD, Marwick JA, Duffin R, Haslett C, et al. Cyclin-dependent kinases 7 and 9 specifically regulate neutrophil transcription and their inhibition drives apoptosis to promote resolution of inflammation. Cell Death Differ 2012;19:1950-61.

96. Kolodziej M, Goetz C, Di Fazio P, Montalbano R, Ocker M, et al. Roscovitine has anti-proliferative and pro-apoptotic effects on glioblastoma cell lines: A pilot study. Oncol Rep 2015;34:1549-56.

97. Kim EH, Kim SU, Shin DY, Choi KS. Roscovitine sensitizes glioma cells to TRAIL-mediated apoptosis by downregulation of survivin and XIAP. Oncogene 2004;23:446-56.

98. Murphy AC, Weyhenmeyer B, Noonan J, Kilbride SM, Schimansky S, et al. Modulation of Mcl-1 sensitizes glioblastoma to TRAILinduced apoptosis. Apoptosis 2014;19:629-42.

99. Pandey V, Ranjan N, Narne P, Babu PP. Roscovitine effectively enhances antitumor activity of temozolomide in vitro and in vivo mediated by increased autophagy and Caspase-3 dependent apoptosis. Sci Rep 2019;9:5012.

100. Menn B, Bach S, Blevins TL, Campbell M, Meijer L, et al. Delayed treatment with systemic (S)-roscovitine provides neuroprotection 
and inhibits in vivo CDK5 activity increase in animal stroke models. PLoS One 2010;5:e12117.

101. Brasca MG, Amboldi N, Ballinari D, Cameron A, Casale E, et al. Identification of N,1,4,4-tetramethyl-8-\{[4-(4-methylpiperazin-1-yl) phenyl]amino\}-4,5-dihydro-1H-pyrazolo[4,3-h]quinazoline-3-carboxamide (PHA-848125), a potent, orally available cyclin dependent kinase inhibitor. J Med Chem 2009;52:5152-63.

102. Albanese C, Alzani R, Amboldi N, Degrassi A, Festuccia C, et al. Anti-tumour efficacy on glioma models of PHA-848125, a multikinase inhibitor able to cross the blood-brain barrier. Br J Pharmacol 2013;169:156-66.

103. Parry D, Guzi T, Shanahan F, Davis N, Prabhavalkar D, et al. Dinaciclib (SCH 727965), a novel and potent cyclin-dependent kinase inhibitor. Mol Cancer Ther 2010;9:2344-53.

104. Nguyen TK, Grant S. Dinaciclib (SCH727965) inhibits the unfolded protein response through a CDK1- and 5-dependent mechanism. Mol Cancer Ther 2014;13:662-74.

105. Chen Z, Wang Z, Pang JC, Yu Y, Bieerkehazhi S, et al. Multiple CDK inhibitor dinaciclib suppresses neuroblastoma growth via inhibiting CDK2 and CDK9 activity. Sci Rep 2016;6:29090.

106. Jane EP, Premkumar DR, Cavaleri JM, Sutera PA, Rajasekar T, et al. Dinaciclib, a cyclin-dependent kinase inhibitor promotes proteasomal degradation of Mcl-1 and enhances ABT-737-mediated cell death in malignant human glioma cell lines. J Pharmacol Exp Ther 2016;356:354-65.

107. Law ME, Corsino PE, Narayan S, Law BK. Cyclin-dependent kinase inhibitors as anticancer therapeutics. Mol Pharmacol 2015;88:846-52.

108. Ali MA, Choy H, Habib AA, Saha D. SNS-032 prevents tumor cell-induced angiogenesis by inhibiting vascular endothelial growth factor. Neoplasia 2007;9:370-81.

109. Ali MA, Reis A, Ding LH, Story MD, Habib AA, et al. SNS-032 prevents hypoxia-mediated glioblastoma cell invasion by inhibiting hypoxia inducible factor-1alpha expression. Int J Oncol 2009;34:1051-60.

110. Chen R, Wierda WG, Chubb S, Hawtin RE, Fox JA, et al. Mechanism of action of SNS-032, a novel cyclin-dependent kinase inhibitor, in chronic lymphocytic leukemia. Blood 2009;113:4637-45.

111. Conroy A, Stockett DE, Walker D, Arkin MR, Hoch U, et al. SNS-032 is a potent and selective CDK 2, 7 and 9 inhibitor that drives target modulation in patient samples. Cancer Chemother Pharmacol 2009;64:723-32.

112. Erbayraktar Z, Alural B, Erbayraktar RS, Erkan EP. Cell division cycle 7-kinase inhibitor PHA-767491 hydrochloride suppresses glioblastoma growth and invasiveness. Cancer Cell Int 2016;16:88.

113. Newcomb EW, Tamasdan C, Entzminger Y, Alonso J, Friedlander D, et al. Flavopiridol induces mitochondrial-mediated apoptosis in murine glioma GL261 cells via release of cytochrome c and apoptosis inducing factor. Cell Cycle 2003;2:243-50.

114. Michaud K, Solomon DA, Oermann E, Kim JS, Zhong WZ, et al. Pharmacologic inhibition of cyclin-dependent kinases 4 and 6 arrests the growth of glioblastoma multiforme intracranial xenografts. Cancer Res 2010;70:3228-38.

115. Whittaker S, Madani D, Joshi S, Chung SA, Johns T, et al. Combination of palbociclib and radiotherapy for glioblastoma. Cell Death Discov 2017;3:17033.

116. Sepulveda-Sanchez JM, Gil MJG, Alonso M, Salgado MÁV, Vicente E, et al. Phase II trial of palbociclib in recurrent RB-positive anaplastic oligodendroglioma: a Spanish group for research in neurooncology (GEINO) trial. J Clin Oncol 2019;37:2038.

117. Patel YT, Davis A, Baker SJ, Campagne O, Stewart CF. CNS penetration of the CDK4/6 inhibitor ribociclib in non-tumor bearing mice and mice bearing pediatric brain tumors. Cancer Chemother Pharmacol 2019;84:447-52.

118. Martinez-Chavez A, van Hoppe S, Rosing H, Lebre MC, Tibben M, et al. P-glycoprotein limits ribociclib brain exposure and CYP3A4 restricts its oral bioavailability. Mol Pharm 2019;16:3842-52.

119. Tien AC, Bao X, Derogatis A, Kim S, Mehta S, et al. ACTR-45. Phase 0/2 study of ribociclib in patients with recurrent glioblastoma. Neuro-Oncology 2018;20:vi21.

120. Raub TJ, Wishart GN, Kulanthaivel P, Staton BA, Ajamie RT, et al. Brain exposure of two selective dual CDK4 and CDK6 inhibitors and the antitumor activity of CDK4 and CDK6 inhibition in combination with temozolomide in an intracranial glioblastoma xenograft. Drug Metab Dispos 2015;43:1360-71.

121. Tolaney SM, Lin NU, Thornton D, Klise S, Costigan TM, et al. Abemaciclib for the treatment of brain metastases (BM) secondary to hormone receptor positive (HR+), HER2 negative breast cancer. J Clin Oncol 2017;35:1019.

122. Tsang J, Sung S, Gosa L, Meetze K, Cloughesy T, et al. EXTH-67. TG02, a brain-penetrant multi-CDK inhibitor, potently suppresses MYC-driven glioblastoma. Neuro Oncol 2017;19:vi87-8.

123. Su YT, Chen R, Wang H, Song H, Zhang Q, et al. Novel targeting of transcription and metabolism in glioblastoma. Clin Cancer Res 2018;24:1124-37.

124. Le Rhun E, von Achenbach C, Lohmann B, Silginer M, Schneider H, et al. Profound, durable and MGMT-independent sensitivity of glioblastoma cells to cyclin-dependent kinase inhibition. Int J Cancer 2019;145:242-53.

125. Wu J, Yuan Y, Cordova C, Aboud O, Penas-Prado M, et al. Phase I trial of TG02 plus dose-dense or metronomic temozolomide for recurrent anaplastic astrocytoma and glioblastoma in adults. J Clin Oncol 2019;37:2031. 